\title{
Probabilistic estimation of annual lost economic production due to premature deaths because of earthquakes
}

Mario A. Salgado-Gálvez, Centre Internacional de Metodes Numerics en Enginyeria (CIMNE) Universitat Politècnica de Catalunya, Barcelona, Spain. mario.sal.gal@gmail.com

Gabriel A. Bernal, Centre Internacional de Metodes Numerics en Enginyeria (CIMNE) Universitat Politècnica de Catalunya, Barcelona, Spain. gabernal@cimne.upc.edu

Alex H. Barbat, Centre Internacional de Metodes Numerics en Enginyeria (CIMNE)

Universitat Politècnica de Catalunya, Barcelona, Spain. alex.barbat@upc.edu

Martha L. Carreño, Centre Internacional de Metodes Numerics en Enginyeria (CIMNE)

Universitat Politècnica de Catalunya, Barcelona, Spain. liliana@cimne.upc.edu

Omar-Darío Cardona, Instituto de Estudios Ambientales (IDEA), Universidad Nacional de

Colombia Sede Manizales, Manizales, Colombia. odcardonaa@unal.edu.co

\section{ACKNOWLEDGMENTS}

The authors are grateful for the support of the Ministry of Education and Science of Spain "Enfoque integral y probabilista para la evaluación del riesgo sísmico en España"CoPASRE (CGL2011-29063). Also to the Spain's Ministry of Economy and Competitiveness in the framework of the researcher's formation program (FPI). Also to two anonymous reviewers who contributed to improve the original version of the manuscript.

Citing this article: Salgado-Gálvez M.A., Bernal G.A., Barbat A.H., Carreño M.L. and Cardona O.D. (2015). Probabilistic estimation of annual lost economic production due to premature deaths because of earthquakes. Human and Ecological Risk Assessment, 22(2), 2016, 543-557, DOI: 10.1080/10807039.2015.1095072 


\begin{abstract}
A methodology to estimate, in a probabilistic way, the annual cost to society of premature deaths because of earthquakes is proposed in this paper. The methodology makes use of results obtained by means of prospective and probabilistic seismic risk assessments where, expected deaths caused by the collapse of buildings are obtained. Those results, combined with demographic and macroeconomic indicators such as the age distribution, life expectancy at birth and per capita gross domestic product, are used to estimate the cost to society in terms of lost productivity due to premature mortality because of earthquakes. The proposed methodology does not attempt to estimate neither assign a cost to human lives at any stage, but the one associated to lost productivity at societal level. One of the descriptors of the methodology is part of the components of the disability adjusted lost years ( $D A L Y)$, a widely used metric in the public health field which estimates the burden of diseases based mostly on historical data. As an example, the methodology is applied to Medellín, the second largest city of Colombia, finding that the cost of lost productivity due to premature mortality because of earthquakes has a similar order of magnitude than the direct physical losses in the public and private building stock calculated in a previous probabilistic seismic risk assessment.
\end{abstract}

\title{
KEYWORDS
}

Probabilistic seismic risk assessment; average annual deaths; earthquake casualties; disability adjusted lost years; CAPRA.
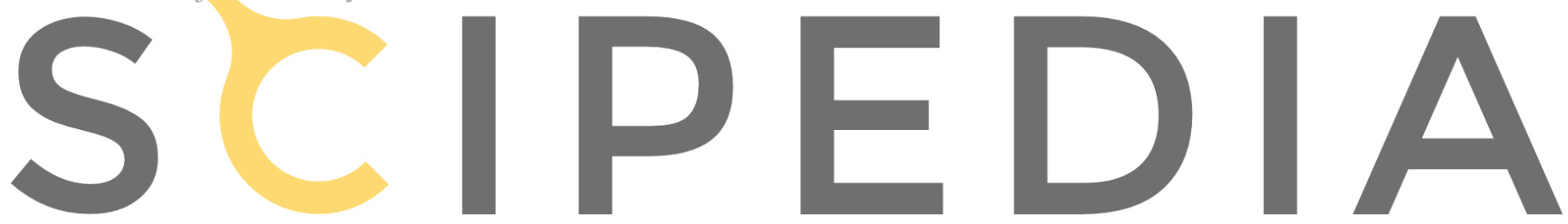

Register for free at https//www.scipedia.com to download the version without the watermark 


\section{INTRODUCTION}

An estimated of 720,000 deaths because of more than 460 earthquakes have been recorded since 1999 around the world (Guha-Sapir et al 2015). Besides being per se a shocking figure, the issue is aggravated with the fact that more than $90 \%$ of them have occurred in developing countries. It has been largely stated that earthquakes do not kill people but structures that collapse do and, poor construction practices besides building codes with low standards and enforcement levels can still be found at worldwide level. Probabilistic seismic risk models allow the estimation of damages and losses on the exposed assets and, depending on the available information also the estimation of casualties, both injured and deaths. Even more, the estimation of casualties is considered one of the most important outputs since the main purpose of any comprehensive seismic risk management scheme is to protect lives (Olson and $\mathrm{Wu} 2010)$.

Most of the published seismic risk assessments have estimated damages and losses on the exposed elements but there have also been cases where deaths associated to earthquakes occurrence have been calculated at different resolution levels (Algermissen et al. 1972; McClure et al. 1979; Reitherman 1982; Marulanda et al. 2013; Salgado-Gálvez et al. 2014a). There are also different approaches to estimate deaths, ranging from single-scenario approaches where only one event of interest is considered, to fully probabilistic assessments where the contributions of several events with different occurrence probabilities are accounted for. Anyhow, it has not yet been proposed a way to estimate the impact and consequences of those deaths in the society apart of calculating the overall figure. This paper proposes a
methodology to estimate the cost to society in terms of the lost production due to premature
mortality because of earthquakes considering demographic and macroedonomic in dexes. It is
important to make it clear that the objective of the proposed methodology is not, by any
means, to assign a value to the lives of the inhabitants of the area under study.

In the public health field, the disability adjusted life year (DALY) is a commonly used metric

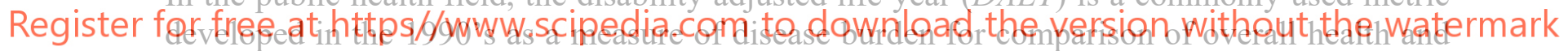

life expectancy in different countries. 1 DALY corresponds then to 1 lost year of healthy life.

According to the methodology proposed by the World Health Organization in the latest release of the global burden of disease (WHO 2013) it is estimated by adding two components as follows

$$
D A L Y=Y L D+Y L L
$$

where $Y L D$ is the adjusted number of years lived with disability and $Y L L$ is the number of years of life-lost due to premature mortality. YLL is calculated as the number of deaths multiplied by the life expectancy at the age of death. The estimation of that metric is based mostly on historical data and, therefore, it can be classified as a retrospective one.

Based on one of the ideas behind the $D A L Y$, the estimation of the average number of years of lost-life due to premature mortality because of earthquakes, $Y L L$, is proposed herein. $Y L L$ consider only those deaths associated to building collapse by using probabilistic catastrophe models (cat-models) instead of historical data, being then a prospective metric.

Regarding $Y L D$, although with state-of-the-art cat-models it is possible to estimate the expected number of injured because of earthquakes, it is not possible to accurately make estimations of the kind of injuries and therefore, the time either to remission or death. Because 
of that, it is not possible to yet estimate $Y L D$ due to earthquakes in a prospective way and, therefore, it is not included in the estimation of lost production.

In the earthquake engineering field, metrics based on DALYs have been proposed, such as the Economic Adjusted Life Years (Scawthorn 2011) which, based on historical earthquake monetary loss estimations and average annual wages per capita, made comparative assessments of earthquakes occurring between 1906 and 2004.

Considering the participation of all the possible earthquakes in the area under analysis, collapse probabilities and fatality rates per building class, the average annual number of deaths $(A A D)$ is estimated and, then, based on demographic data such as age distribution and life expectancy at birth, the average number of years of lost-life due to premature mortality because of earthquakes is estimated. Finally, an order of magnitude, in terms of lost productivity associated to the average annual number of years of life-lost due to premature mortality is obtained.

The importance to reduce disaster casualties has been acknowledged by the Tokyo Metropolitan Government, who has announced to follow specific and measurable risk reduction targets to achieve this goal (RMS 2015). The use and development of vulnerability functions to estimate deaths associated to earthquakes following the methodology proposed in this paper can help to assess the performance of certain goals.
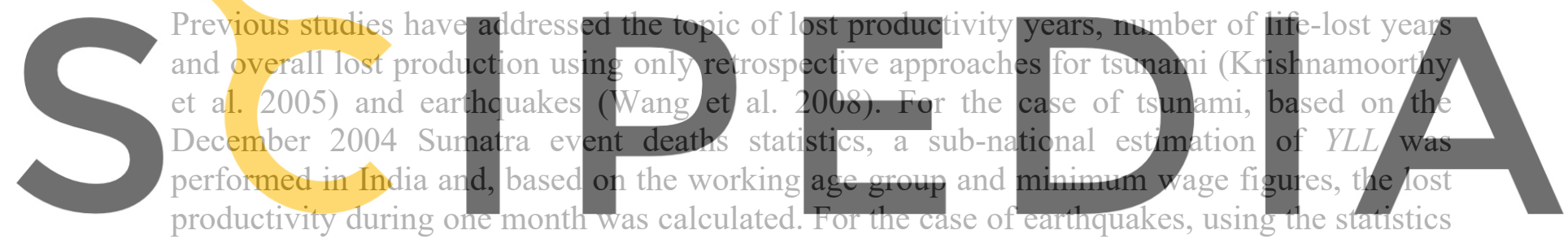

of the 2008 Wenchuan event, the effect of injuries in public health of China in terms not only

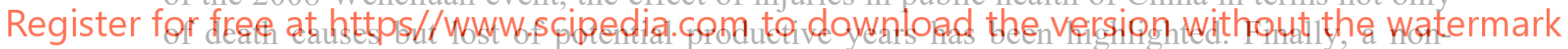

monetary metric to account for the direct impact of natural disasters with different origins was introduced by Noy $(2014,2015)$ and applied at global level based also in disaster databases. Although the estimation of the impact in this dimension is very useful, it is also known that for catastrophic events the scarce historical data is not enough to have a complete overview of the problem and, therefore, prospective and probabilistic approaches such as the used herein are proposed.

The results that can be obtained with this methodology can also contribute to raise risk awareness, besides allowing the development and promotion of risk mitigation strategies through increasing building code compliance in case of new buildings and by promoting structural retrofitting schemes for the case of existing ones (at least in buildings classified as critical facilities), bearing in mind that the main objective of them is to protect the life of its occupants which in an indirect way serves also as a measure to protect wealth and property. The results obtained with this proposed methodology should be seen as complementary to the ones obtained with the traditional probabilistic risk assessments performed for the built stock. Also, since the objective of the methodology is to estimate the lost production, the YLL is needed instead of the classical estimation of people killed by earthquakes which are expressed in number of deaths.

An application of the proposed methodology is presented for Medellín, Colombia, which is an 
urban center with more than two million inhabitants that lies in and intermediate seismic hazard zone (AIS 2010). The results of lost productivity are compared against those previously estimated for the city that only considered the direct losses on the public and private building portfolio (Salgado-Gálvez et al. 2014b) and it is shown how the ratio between the losses is higher than the unit, reason why this proposed approach should also be considered within a comprehensive seismic risk management framework.

\section{PROBABILISTIC SEISMIC RISK ASSESSMENT}

This section presents a summary of the methodology used for the prospective estimation of deaths because of earthquakes. It follows a probabilistic approach from the hazard and vulnerability perspective where different requirements need to be fulfilled.

When modeling earthquake risk, one must be aware of the large amount of uncertainties related mainly to the hazard and to the vulnerability (Ordaz 2000; Grossi 2004; Murphy et al. 2011; Marulanda et al. 2013; Salgado-Gálvez et al. 2014b; Salgado-Gálvez et al. 2015a). Because of that, those uncertainties need to be quantified and rigorously propagated through the loss estimation process and it can only be achieved if probabilistic risk models are used. The inputs for the risk model can be classified into the following three categories: 1) hazard; 2) exposure and 3) vulnerability. For the hazard representation, a set of stochastic events that contain all the possible ways in which earthquakes may manifest in the area under analysis is required. The events need to be collectively exhaustive, mutually exclusive and describe the spatial and temporal variation of the hazard. Exposure can be modelled at different resolution levels, ranging from doa of characterization of the material, number of stories, structural system an Finally, vulnerability functions that relate difice
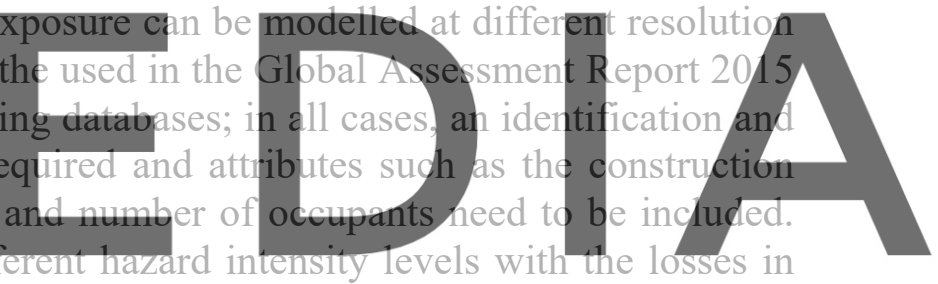

the exposed elements are assigned to each building class. Losses can have different

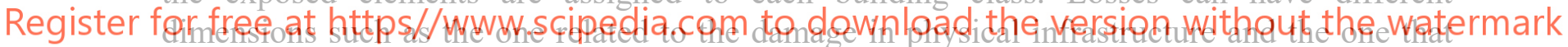
accounts for the human affection. The latter is the one of interest in the methodology proposed herein.

Since it is not possible to directly calculate the probability distribution function of losses conditional to the occurrence of an event, the following procedure proposed by Ordaz (2000) is used

$$
f\left(l_{j} \mid \text { Event }_{i}\right)=\int_{0}^{\infty} f\left(l_{j} \mid S a\right) f\left(S a \mid \text { Event }_{i}\right) d S a
$$

In equation 2, two different conditional probability functions are chained, where the first one has to do with the vulnerability (the expected loss given a hazard intensity) and the second part with the hazard (the hazard intensity given the occurrence of the event).

One of the most robust probabilistic risk metrics is the average annual loss $(A A L)$ (Marulanda 2013) which can be computed using the following equation:

$$
A A L=\sum_{i=1}^{N} \mathrm{E}\left(L \mid \text { Event }_{i}\right) \cdot F_{A}\left(\text { Event }_{i}\right)
$$


where $\mathrm{E}\left(L \mid\right.$ Event $\left._{i}\right)$ is the mean loss value given the occurrence of the $i^{\text {th }}$ event and $F_{A}\left(\right.$ Event $\left._{i}\right)$ is the associated annual occurrence frequency of the same event. This approach requires an exhaustive set of hazard events which can be obtained by using probabilistic seismic hazard assessment (PSHA) programs like CRISIS2008 (Ordaz et al. 2013). Nevertheless, in some cases, seismic hazard information is not available in that representation but in terms of intensity exceedance curves (also known as hazard curves) which, in the case of earthquakes usually relate acceleration levels with their corresponding annual exceedance rates. Based on that information, it is also possible to calculate the $A A L$ by using the following expression:

$$
A A L=\sum_{i=1}^{K} \int_{0}^{\infty}-\frac{d v(a)}{d a} \cdot E(l \mid a)_{i} \cdot d a
$$

In this case $v(a)$ is the annual hazard intensity exceedance rate, $K$ is the total number of exposed assets, $a$ is the hazard intensity and $E(l \mid a)$ is the expected value of the loss given a hazard intensity a in the $i^{\text {th }}$ exposed element. If PSHA has been performed in a rigorous and exhaustive way, the use of either equations 2 or 3 , would lead to the same value of $A A L$.

Within a probabilistic risk assessment framework, the vulnerability functions allow obtaining losses in different dimensions such as monetary losses and casualties. These functions relate the expected hazard intensities with the expected consequences and efforts have been made worldwide to develop and deaths, associated to 2009; Jaiswal and Wald 2 (a)

surveys. It is well-known that this is a difficult deaths can be observed from event to event, magnitudes, depths and building stock chara
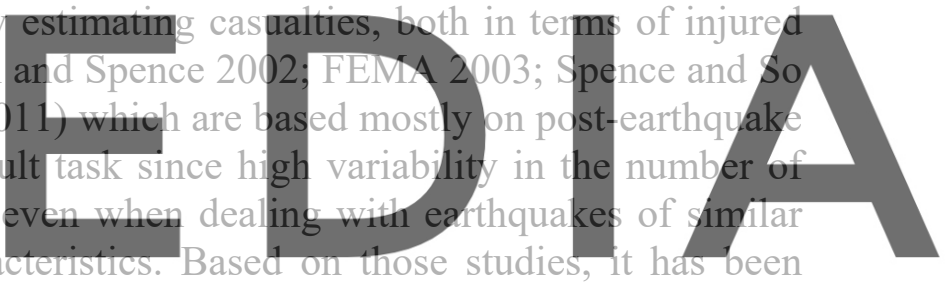
possible to define lethality rates by building class to estimate the expected deaths for each

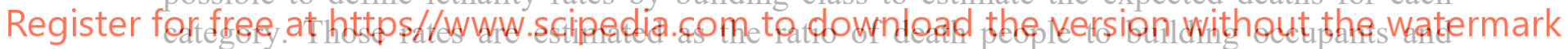

depend on the building class and collapse mechanism, among some other structural characteristics. Also, regardless the building class, the fatality rates tend to increase with the number of stories. Figure 1 shows the vulnerability function in terms of the expected value of lethality rates for high-rise reinforced concrete dwellings as an example. The hazard intensity is the spectral acceleration at the fundamental elastic period of the structure which is the hazard parameter that better correlates the expected damage and losses (Luco and Cornell 2007).

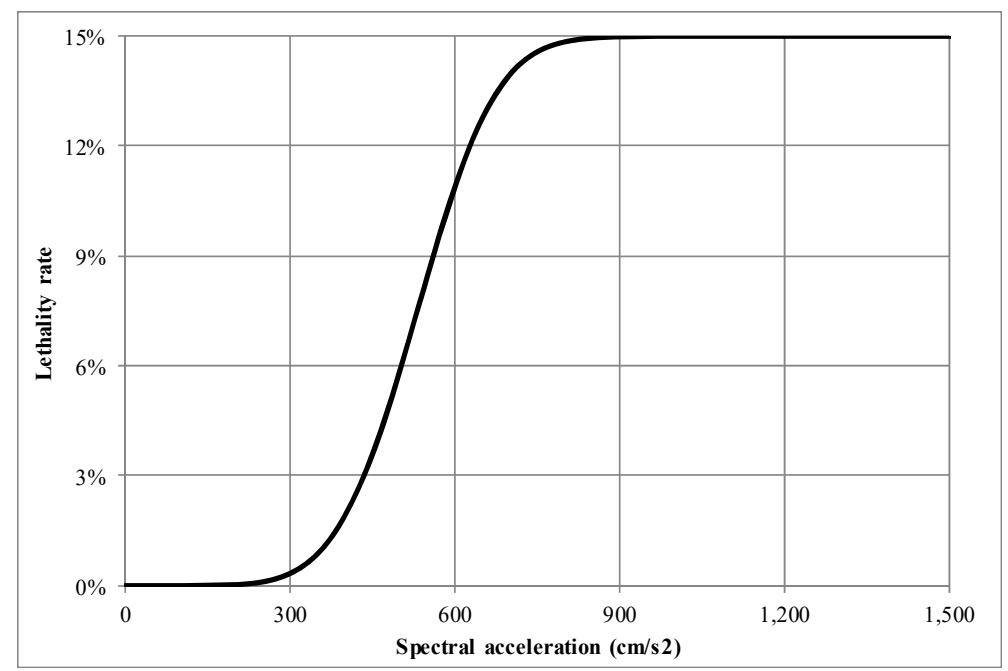


Figure 1 Example of deaths vulnerability function for high-rise reinforced concrete dwellings

It is worth mentioning that only indoor mortality is considered with these functions but it is also the case where most of the deaths occur, not ignoring that people exposed to failing objects outdoors can also be affected.

\section{PROPOSED METHODOLOGY}

The proposed methodology is presented herein and each of the input data needed to estimate the average annual production cost lost due to premature mortality because of earthquakes are explained. It is important to mention that the methodology can be applied considering other hazards such as tropical cyclones, volcanic ash and tsunami, as long as vulnerability functions that allow estimating deaths associated to them can be developed and the available hazard representation allows estimating average annual losses. Also, the proposed methodology can be applied at different resolution levels, an issue that provides opportunities to estimate the cost to society for example at country, subnational and/or local level.

Estimation of the Average Annual Deaths

Estimation of deaths caused by the collapse of buildings during an earthquake using state-ofthe-art risk models still constitutes a big challenge (Ferreira et al. 2011). It is not only because population data to be included in the exposure databases are a dynamic parameter that depends on the day, time and even season but also, because the existing casualties' consequences databasesprovide loss dimension for the earthquakes at this stag like tsunami, landslides deaths during earthqua has been established thet
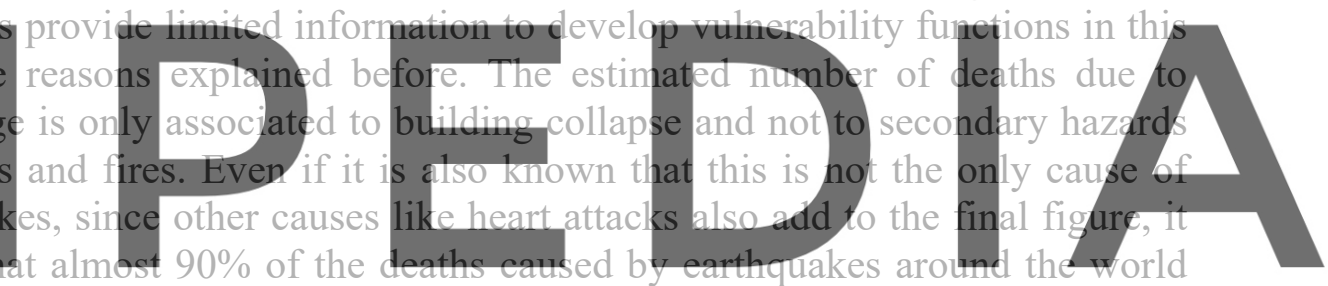

are due to structural collapse (Coburn and Spence 2002)

Register for free at https//www.scipedia.com to download the version without the watermark

The first input to the calculation is the average annual deaths ( $A A D$ ) because of earthquakes, a metric that is based on the same basis and assumptions than the AAL, which can be summarized as: 1) it considers the participation of all possible earthquakes; 2) an infinite timeframe for the occurrence of the events is assumed and 3) damaged structures are rebuilt or repaired to meet the initial conditions after they have been damaged; the same applies to the human occupation levels.

Analogously to the $A A L$ presented in Equation 3, the $A A D$ because of earthquakes can then be obtained and can be computed directly when using an event-based risk assessment by means of

$$
A A D=\sum_{i=1}^{N} E\left(\mathrm{D} \mid \text { Event }_{i}\right) \cdot F_{A}\left(\text { Event }_{i}\right)
$$

where $N$ is the total number of representative hazard events, $F_{A}(E v e n t$ i) is the annual frequency of occurrence of the $i^{t h}$ hazard event and $E(\mathrm{D} \mid$ Event $\mathrm{i})$ are the expected deaths because of collapse of the exposed assets given that the $i^{t h}$ event occurred. In the cases where no stochastic representation for the seismic hazard is available, Equation 4 can be used bearing in mind that the estimated loss has a human deaths dimension. Since occupancy is a dynamic parameter and, neither its daily or seasonal variations can be well established, 
average occupancy rates like the ones proposed by Liel and Dierlein (2012) that account for occupancy ratios according to day and time of the day can be used.

If $A A D$ is calculated for other hazards, it can be added arithmetically since it corresponds to an expected value. This allows the implementation of the proposed methodology in multihazard risk assessments, suitable for areas where more than one hazard can cause significant consequences to its inhabitants.

\section{Age Distribution}

Based on censual data, it is possible to establish the age distribution of the inhabitants the area under analysis. Usually, the data are grouped into age ranges of 5 to 10 years spans and are updated on a regular basis. The age distributions to be used in the proposed methodology correspond to the most updated at the moment of the analysis. Assuming that there are $M$ age ranges, the population distribution can be estimated for each of them and denoted as $P r$. A uniform age distribution based on the demographic statistics is assumed for the area of analysis. Since all the inhabitants fall only into one of the age ranges, the following condition is met

\section{$\sum^{M} P_{r}=1.0$}

(Eq. 6)
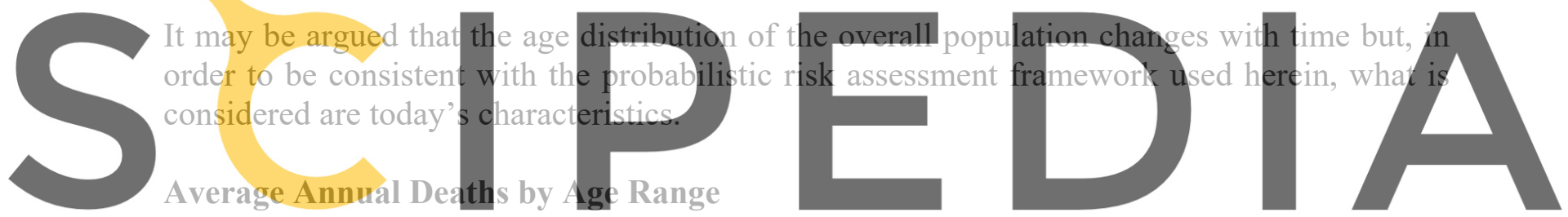

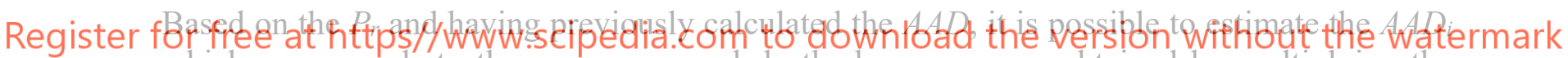
which corresponds to the average annual deaths by age range, obtained by multiplying the total $A A D$ by the correspondent $P_{r}$ factor. This step assumes that the age distribution of the deaths because of earthquakes have the same characteristics as that for the base population, which can be considered an appropriate assumption in the case of earthquakes since, in the type of injuries that cause deaths, the age factor does not constitute a differential cause. In all cases:

$$
\sum_{i=1}^{M} A A D_{i}=A A D
$$

\section{Life Expectancy at Birth}

Life expectancy at birth is usually available from official sources given its importance in different social, security, economic and public health aspects. For the area under analysis a unique value for it is needed in this proposed methodology, reason why, if the available information is disaggregated by for example, gender or smaller geographical units, a weighted average can be calculated. Unitary years of lost-life because any cause by age ranges $\left(L_{i}\right)$ can be obtained by calculating the difference between the life expectancy at birth and the mean value of the age range (i.e. if the age range is 20-24 years, the mean value is 22.5 years). With this, it is being assumed that years within each age range are uniformly distributed. Life 
expectancy at birth at the moment of the analysis is to be used again to be consistent with the probabilistic risk assessment framework.

\section{Years of Life-Lost due to Premature Mortality Because of Earthquakes}

By multiplying $L_{i}$ by $A A D_{i}$, the $Y L L_{i}$ are obtained corresponding thus to the average annual number of years of life-lost due to premature mortality because of earthquakes by age range. Since this is an expected value, it can be arithmetically added and, the sum of the $Y Y L_{i}$ of the $M$ age ranges corresponds to the overall average annual number of years of life-lost due to premature mortality because of earthquakes for the area under analysis $(Y L L)$

$Y L L=\sum_{i=1}^{M} Y L L_{i}$

Average Annual Lost Productivity Cost due to Premature Mortality Because of Earthquakes

To relate the average annual number of years of life-lost due to premature mortality because of earthquakes with its consequences on production, the gross domestic product (GDP) per capita is used. It is widely accepted that GDP is the economic index that best measures economic welfare and, that due to the characteristics of an economy it can either represent the income of all the members of an economy or the total expenditure in the production of goods and services in it. DALYS estimations in some cases have appraised the years acco
age, based on the fact that it is during the working-age range that the peak product
for each individual; this procedure is known as social weighting (WHO 2004). In
the estimation of the lost productivity only considers the YLLi associated to the
population which, according to the Organization for Economic Co-ope Development (OECD), is constituted by those aged 15 to 64 (OECD 2014). Within that range,

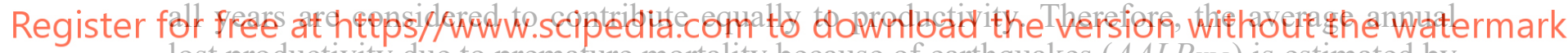
lost productivity due to premature mortality because of earthquakes (AALPYLL) is estimated by means of

$$
A A L P_{Y L L}=Y L L_{(15-64)} \cdot G D P_{\text {/capita }}
$$

It is important to bear in mind that the same assumptions made for the calculation of $A A L$ apply to the $A A L P_{Y L L}$, from where the most important is, that the estimated cost represents an average value which can be interpreted as the long term annualized cost of lost productivity due to premature deaths caused by possible earthquakes with different magnitude, depth and location. This approach also follows the premise that saving a life is independent of the life saved.

Both $A A D$ and $A A L P_{Y L L}$ are relevant risk metrics that cover a dimension which, so far, has not been explicitly addressed in a probabilistic and prospective way. In most probabilistic risk assessments only direct losses associated to physical damages of the built stock are obtained and in some cases used as a basis for the estimation of economic flow variations that account for the indirect losses; none of them account for the expected lost productivity due to premature mortality and this innovative proposal aims to cover that field which may be of special importance in dense population settlements located in earthquake prone regions. The estimation of $A A L P_{Y L L}$ also serves as a basis to estimate the order of magnitude of what a 
society should be willing to spend to protect and save itself against natural disasters (Rosenblueth 1976).

The proposed methodology has some limitations that are important to highlight with the objective of promoting future research that may contribute to improvements. First, only the life-years lost due to premature mortality are considered herein and it would be desirable to be able to estimate $Y L D$ and assess its impact in terms of lost productivity. Second, deaths associated to other damage states different than collapse and occurring outdoors, although being a small fraction, if considered will provide a comprehensive framework for deaths estimation and subsequent lost productivity assessment.

\section{APPLICATION AT URBAN LEVEL IN MEDELLÍN, COLOMBIA}

The proposed methodology is applied to Medellín, Colombia. The city has more than two million inhabitants and is located on an intermediate seismic hazard zone with peak ground accelerations (PGA) of $0.15 \mathrm{~g}$ associated to a mean return period of 475 years (AIS 2009; Salgado-Gálvez et al. 2010; 2015b). The city has complete and high quality information regarding the different aspects that are required for the analysis and the results are presented herein.

First, the estimation of $A A D$ is performed using the program CAPRA-GIS (ERN-AL 2011) which is the probabilistic risk calculator of the CAPRA Platform ${ }^{1}$ (Cardona et al. 2010, 2012; Marulanda et al. 2013; Velásquez et ah. 2014). The input data in terms of seismic hazard and exposure are the same as those used for the estimation of 10 s (Salgado-Gálvez et al. 2014b) but the yulnerability functions, interest in this case is different, are in terms of lethality $r$ summary, the seismic hazard is with more than 1,800 stochastic events and, spectral transfer functions are also defined for the different soil zones to account for the dynamic soil response which is not negligible in the

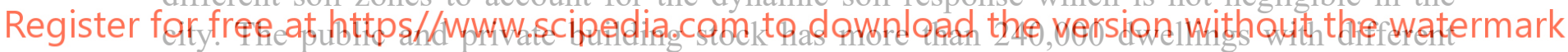

structural characteristics whose details can be found in Salgado-Gálvez et al. (2014b). Urban population projected for year 2015 is equal to 2,218,192 inhabitants (DANE and Aicaldía de Medellín 2010) and is distributed by buildings considering their main use and making use of official population density data. An occupation rate of $60 \%$, following the distributions proposed by Liel and Dierlein (2012) has been assumed. This is needed since more than 1,800 possible earthquakes, with different magnitudes, locations and occurrence frequencies are considered in the analysis for which the day and time of occurrence is unknown.

$A A D$ is estimated in 2,187 people for Medellín which in relative terms correspond to $0.99 \%$ of the total population count. Higher values are expected for reinforced concrete buildings of medium and high-rise if compared to the non-engineered low-rise structures made of wood and zinc that do not cause as many deaths in case of collapse if compared with middle and high-rise reinforced concrete frames.

Based on the official demographic information (DANE and Alcaldía de Medellín 2010), age distribution by 5 year span ranges is available as shown in Table 1.

Table 1 Age distribution

\footnotetext{
${ }^{1}$ www.ecapra.org
} 


\begin{tabular}{|c|c|c|}
\hline Age range & $\begin{array}{c}\text { Number of } \\
\text { inhabitants }\end{array}$ & $\begin{array}{c}\text { Relative } \\
\text { number of } \\
\text { inhabitants }\end{array}$ \\
\hline 0 to 4 & 127,152 & $5.73 \%$ \\
\hline 5 to 9 & 131,189 & $5.91 \%$ \\
\hline 10 to 14 & 132,672 & $5.98 \%$ \\
\hline 15 to 19 & 151,863 & $6.85 \%$ \\
\hline 20 to 24 & 169,467 & $7.64 \%$ \\
\hline 25 to 29 & 182,798 & $8.24 \%$ \\
\hline 30 to 34 & 168,471 & $7.59 \%$ \\
\hline 35 to 39 & 147,581 & $6.65 \%$ \\
\hline 40 to 44 & 130,319 & $5.88 \%$ \\
\hline 45 to 49 & 168,822 & $7.61 \%$ \\
\hline 50 to 54 & 181,808 & $8.20 \%$ \\
\hline 55 to 59 & 158,137 & $7.13 \%$ \\
\hline 60 to 64 & 125,673 & $5.67 \%$ \\
\hline 65 to 69 & 92,907 & $4.19 \%$ \\
\hline 70 to 74 & 58,501 & $2.64 \%$ \\
\hline 75 to 79 & 43,606 & $1.97 \%$ \\
\hline $80+$ & 47,226 & $2.13 \%$ \\
\hline TOTAL & $\mathbf{2 , 2 1 8 , 1 9 2}$ & $\mathbf{1 0 0 \%}$ \\
\hline
\end{tabular}

With this information, it is now possible to estimate $A A D_{i}$ as presented in Table 2. As explained, the sum of the $A A D_{i}$ corresponds to the overall $A A D$. 
Table 2 Average annual deaths by age range

\begin{tabular}{|c|c|}
\hline Age range & $\boldsymbol{A A D \boldsymbol { }}$ \\
\hline 0 to 4 & 125 \\
\hline 5 to 9 & 129 \\
\hline 10 to 14 & 131 \\
\hline 15 to 19 & 150 \\
\hline 20 to 24 & 167 \\
\hline 25 to 29 & 180 \\
\hline 30 to 34 & 166 \\
\hline 35 to 39 & 146 \\
\hline 40 to 44 & 128 \\
\hline 45 to 49 & 166 \\
\hline 50 to 54 & 179 \\
\hline 55 to 59 & 156 \\
\hline 60 to 64 & 124 \\
\hline 65 to 69 & 92 \\
\hline 70 to 74 & 58 \\
\hline 75 to 79 & 43 \\
\hline $80+$ & 47 \\
\hline TOTAL & $\mathbf{2 , 1 8 7}$ \\
\hline
\end{tabular}

Medellín is divided into 16 counties (comunas) that have similar geographical extension but different socioeconomic characteristics. Since life expectancy at birth corresponds to a metric that has different values even when considering the same urban center because of social, safety and public health issues, available data are disaggregated, in this case at county level. Since the main objective of the proposed methodology is to make an estimation of the cost associated to the lost productivity due to premature mortality because of earthquakes, a single value is needed for the city. For that reason, based on the number of inhabitants in each county shown in Table 3, a weighted average of the life expectancy at birth estimated in 76.96 years has been calculated. 
Table 3 Life expectancy at birth and population distribution by county

\begin{tabular}{|c|c|c|c|}
\hline County & $\begin{array}{c}\text { Life expectancy } \\
\text { at birth }\end{array}$ & Population & \% Population \\
\hline Popular & 74.98 & 130,369 & $5.88 \%$ \\
\hline Santa Cruz & 76.04 & 111,452 & $5.02 \%$ \\
\hline Manrique & 75.52 & 159,658 & $7.20 \%$ \\
\hline Aranjuez & 77.01 & 162,252 & $7.31 \%$ \\
\hline Castilla & 78.47 & 149,751 & $6.75 \%$ \\
\hline Doce de Octubre & 77.23 & 193,657 & $8.73 \%$ \\
\hline Robledo & 73.95 & 171,660 & $7.74 \%$ \\
\hline Villa Hermosa & 76.36 & 137,527 & $6.20 \%$ \\
\hline Buenos Aires & 75.75 & 136,774 & $6.17 \%$ \\
\hline La Candelaria & 75.83 & 85,505 & $3.85 \%$ \\
\hline Laureles Estadio & 79.09 & 122,243 & $5.51 \%$ \\
\hline La América & 78.82 & 96,278 & $4.34 \%$ \\
\hline San Javier & 73.82 & 138,063 & $6.22 \%$ \\
\hline Poblado & 81.69 & 128,839 & $5.81 \%$ \\
\hline Guayabal & 78.58 & 97,470 & $4.39 \%$ \\
\hline Belén & 78.99 & 196,694 & $8.87 \%$ \\
\hline
\end{tabular}

At this stage it is possible to estimate the $Y L L i$ of earthquakes as shown in Table 4 which, as expected, shows lower values for advanced ages if compared with younger ones. 
Table 4 Annual years of life-lost due to premature mortality because of earthquake by age range

\begin{tabular}{|c|c|}
\hline Age range & $\boldsymbol{Y L L i}$ \\
\hline 0 to 4 & 9,335 \\
\hline 5 to 9 & 8,985 \\
\hline 10 to 14 & 8,432 \\
\hline 15 to 19 & 8,903 \\
\hline 20 to 24 & 9,100 \\
\hline 25 to 29 & 8,915 \\
\hline 30 to 34 & 7,385 \\
\hline 35 to 39 & 5,742 \\
\hline 40 to 44 & 4,428 \\
\hline 45 to 49 & 4,904 \\
\hline 50 to 54 & 4,385 \\
\hline 55 to 59 & 3,035 \\
\hline 60 to 64 & 1,792 \\
\hline 65 to 69 & 867 \\
\hline 70 to 74 & 257 \\
\hline 75 to 79 & 84 \\
\hline $80+$ & - \\
\hline TOTAL & $\mathbf{8 6 , 5 5 0}$ \\
\hline
\end{tabular}

Sum of the $Y L L_{i}$ equals the total number of years of life-lost due to premature mortality because the earthquakes (YLL) which in this case corresponds to 86,550. Because the highest age range exceeds the life expectancy at birth, it is not added to the final result. Finally, to estimate the cost to society of these deaths as lost future productivity, YLL for ages between 15 and 64 years, equal to 58,589 are multiplied by the GDP per capita. For the case of Medellín that value has been established in US\$11,466 for 2014 (Brookings Institute 2015). With the data for this case study, that value corresponds to US\$672 million which is approximately 1.1 times the value of the $A A L$ that considers only direct damage to the building portfolio (Salgado-Gálvez et al. 2014b).

\section{CONCLUSIONS}

A methodology to estimate in a probabilistic and prospective way the economic cost in terms of lost production of the average annual number of years of life-lost has been presented herein. This metric can serve as a risk awareness measure, representing a step forward into the casualties' estimation field. The proposed methodology in one hand allows estimating in a prospective way the $A A D$ which, when combined with demographic data, allows calculating $A A L P Y L L$ also in a prospective way, to account for the lost production. On the other hand, the proposed methodology can also be useful as a complementary metric to traditional risk assessments that only consider direct damages and losses to the built infrastructure. Since at the end the results of the built stock risk assessments and the AALPYLL are expressed in monetary units, it seems reasonable to combine and compare the results to obtain a wider overall risk perspective.

$A A D$, besides being a robust and compact risk metric, is also a flexible one, since its estimation can be performed using different representations for the hazard, such as stochastic events or hazard curves. On the one hand stochastic events are generally preferred within the fully probabilistic risk modeling frameworks but, on the other hand, hazard is still widely 
represented through maps for different mean return periods in several regions of the world, from where the hazard curves can be obtained and that information be used for the estimation of $A A D$.

The possibility of estimating the number of life-lost years due to premature mortality because of earthquakes and their cost in terms of economic production in a prospective way constitutes a novel approach in which its main benefit can be seen as possibilities of developing ex-ante measures within a comprehensive disaster risk management scheme. Also, since the results are obtained in monetary units, they can be combined with the risk assessments which consider only direct damages and losses on the exposed stock to provide a more comprehensive catastrophic risk panorama of the area under analysis.

The methodology can be used at different resolution levels as long as the exposure databases contain information related to the building typologies and occupation levels. For most cases, seismic hazard at bedrock level and vulnerability functions do not require relevant changes but if local assessments are to be developed, detailed exposure databases and accounting for the dynamic soil response may be needed. National and sub-national assessments of $A A L P Y L L$ can be useful for both the performance assessment of disaster risk reduction actions as well as for comparing the overall risk levels. For national and sub-national assessments, the assumption of all years contributing the same to productivity may not hold and a differentiation or urban and rural areas, economic sectors and working age ranges may be needed.

It has been shown in the case study for Medellín that the annual cost of lost production associated to that cause can even exceed the one estimated for the direct damages on buildings; this can be interpreted as a credible result considering the importance as an economic and industrial hub of the city combined with the low seismic risk awareness and associated seismic vulnerability of the built stock.

Because in some cases the age distributions and life expectancy at birth are available by gender, the methodology can be applied to explore differences among them, serving as a comparative measure in a field that has been identified as important in the disaster risk management field (Enarson et al. 2007). Also, the inclusion of the YLD estimation in the overall lost production is identified as a field of future research where, based on the disaster databases for earthquakes a disaggregation of injuries by type, severity and recovery time may be obtained.

The application of the methodology can be expanded to other hazards and, even more, since $A A D$ corresponds to a mathematical expectation, results can be directly added within the framework of multi-hazard analysis (Ordaz 2015; Jaimes et al. 2015). This is of special importance in areas where low frequency and high impact events associated to different origins (i.e. geological, meteorological) can occur and cause deaths.

\section{REFERENCES}

AIS (Asociación Colombiana de Ingeniería Sísmica). 2010. Estudio General de la Amenaza Sísmica de Colombia. Comité AIS-300. Bogota D.C., Colombia.

Algermissen ST, Dewey J and Rinehart W. 1972. A study of earthquake losses in the San Francisco Bay area; data and analysis. National Oceanic and Atmospheric Administration. USA. 
Brookings Institute. 2015. 2014 Global Metro Monitor Map. Available at: http://www.brookings.edu/research/reports2/2015/01/22-global-metro-monitor

Cardona OD, Ordaz M, Reinoso E, Yamin LE and Barbat AH. 2010. Comprehensive Approach to Probabilistic Risk Assessment (CAPRA): International initiative for disaster risk management effectiveness. Proceedings of the $14^{\text {th }}$ European Conference on Earthquake Engineering. Ohrid, Macedonia.

Cardona OD, Ordaz M, Reinoso E, Yamin LE and Barbat AH. 2012. CAPRA-Comprehensive Approach to Probabilistic Risk Assessment: International initiative for risk management effectiveness. Proceedings of the $15^{\text {th }}$ World Conference on Earthquake Engineering. Lisbon, Portugal.

Coburn A and Spence R. 2002. Earthquake Protection $2^{\text {nd }}$ Edition. John Wiley \& Sons. Chichester, England, UK.

DANE (Departamento Administrativo Nacional de Estadística) and Alcaldía de Medellín. 2010. Proyecciones de Población Municipio de Medellín por edad, sexo, comunas y corregimientos. Available at: https://www.medellin.gov.co/irj/go/km/docs/wpccontent/Sites/Subportal\%20del\%20Ciud adano/Planeaci\%C3\%B3n\%20Municipal/Secciones/Indicadores $\% 20 \mathrm{y} \% 20 \mathrm{Estad} \% \mathrm{C} 3 \% \mathrm{~A}$ Dsticas/Documentos/Proyecciones\%20de\%20poblaci\%C3\%B3n\%202005\%20$\% 202015 / 08 \% 20$ Proyecciones $\% 20$ Poblaci $\%$ C3\%B3n\%20Medell $\% \mathrm{C} 3 \% \mathrm{ADn} \% 202005$ 2015\%20por $\% 20$ comuna_correg\%20y\%20Grupos\%20de $\% 20$ Edad.pdf

Enarson E, Fothergill A and Peek L. 2007. Gender and Disaster: foundations and directions. In: Rodríguez H, Quarantelli E and Dynes R (eds), Handbook of Disaster Research, pp 130-146. Springer.

ERN-AL (Evaluación de Riesgos Naturales América Latina). 2011. CAPRA-GIS v2.0. Program for probabilistic risk assessment. Available at http://www.ecapra.org

FEMA (Federal Emergency Management Agency). 2003. Multi-hazard Loss Estimation Methodology. Earthquake Model. HAZUS-HM MR4. Washington, DC, USA.

Ferreira MA, Oliveira CS and Mota de Sá F. 2011. Estimating human losses in earthquake models: A discussion. In: Spence R, So E and Scawthorn C (eds), Human Casualties in Earthquakes, pp 255-266. Springer.

Grossi P. 2004. Sources, nature and impact of uncertainties on catastrophe modeling. Proceedings of the $13^{\text {th }}$ World Conference on Earthquake Engineering. Vancouver, Canada.

Guha-Sapir D, Below R and Hoyois Ph. 2015. EM-DAT: International Disaster Database. Université Catholique de Louvain. Brussels, Belgium.

Jaimes MA, Reinoso E and Esteva L. 2015. Risk Analysis for Structures Exposed to Several Multi-Hazard Sources. j. of earthq. eng. 19:297-312. 
Jaiswal K and Wald D. 2010. An Empirical Model for Global Earthquake Fatality Estimation. Earthq. spectra 26(4):1017-1037.

Jaiswal KS, Wald DJ, Eartle PS, Porter KA and Hearne M. 2011. Earthquake Casualty Models Within the USGS Prompt Assessment of Global Earthquakes for Response (PAGER) System. In: Spence R, So E and Scawthorn C (eds), Human Casualties in Earthquakes, pp 83-94. Springer.

Krishnamoorthy K, Harichandrakumar KT, Krishna-Kumari A and Das PK. 2005. Years of life lost and productivity loss due to tsunami in India. Curr. Sci. 89(5):739-740.

Liel AB and Deierlein GC. 2012. Using collapse risk assessments to inform seismic safety policy for older concrete buildings. Earthq. spectra 28(4):1495-1521.

Luco N and Cornell CA. 2007. Structure-specific scalar intensity measures for near-source and ordinary earthquake ground motions. Earthq. spectra 23(2):357-392.

Marulanda MC. 2013. Modelación probabilista de pérdidas económicas por sismo para la estimación de la vulnerabilidad fiscal del Estado y la gestión financiera del riesgo soberano. Ph.D. Thesis. Technical University of Catalonia, Barcelona, Spain.

Marulanda MC, Carreño ML, Cardona OD, Ordaz M and Barbat AH. 2013. Probabilistic earthquake risk assessment using CAPRA: application to the city of Barcelona, Spain. Nat. Hazards 69:59-84.

McClure FE, Degenkolb HJ, Steinbrugge KV and Olson RA. 1979. Evaluating the Seismic Hazard of State Owned Buildings. California Seismic Safety Commission. Sacramento, CA, USA.

Murphy C, Gardoni P and Harris Jr. CE. 2011. Classification and moral evaluation of uncertainties in engineering modeling. Sci. eng. ethics 17:553-570.

Noy I. 2014. A non-monetary global measure of the direct impact of natural disasters. Background paper of the 2015 Global Assessment Report on Disaster Risk Reduction. Geneva, Switzerland.

Noy I. 2015. Comparing the direct human impact of natural disasters for two cases in 2011: The Christchurch earthquake and Bangkok flood. Int. J. of disaster risk reduct. 13:61-65.

OECD (Organization for Economic Co-operation and Development). 2014. OECD Employment Outlook 2015. OECD Publishing. doi:10.1787/empl_outlook-2014-en

Olson DL and Wo DD. 2010. Earthquakes and Risk Management in China. Hum. Ecol. Risk Assess. 16(3):478-493.

Ordaz M. 2000. Metodología para la evaluación del riesgo sísmico enfocada a la gerencia de seguros por terremoto. Universidad Nacional Autónoma de México. Mexico City, Mexico. 
Ordaz M. 2015. A simple probabilistic model to combine losses arising from the simultaneous occurrence of several hazards. Nat. Hazards 76:389-396.

Ordaz M, Martinelli F, D'Amico V and Meletti C. 2013. CRISIS2008: A flexible tool to perform probabilistic seismic hazard assessments. Seismol. res. lett. 84(3):495-504.

Reitherman R. 1982. Computer-Aided Earthquake Analysis and Planning for Business and Organizations. National Science Foundation. USA.

RMS (Risk Management Solutions) 2015. RMS Commends Tokyo's "50 Percent Initiative2 for setting targets to reduce disaster casualties. Press release Available at: http://www.rms.com/about/newsroom/press-releases/press-detail/2015-04-07/rmscommends-tokyos-50-percent-initiative-for-setting-targets-to-reduce-disaster-casualties

Rosenblueth E. 1976. Towards optimum design through building codes. J. of the struct. div. American Society of Civil Engineers ST3:591-607.

Salgado-Gálvez MA, Bernal GA, Yamin LE and Cardona OD. 2010. Evaluación de la amenaza sísmica de Colombia. Actualización y uso en las nuevas normas colombianas de diseño sismo resistente NSR-10. Rev. de Ing. Universidad de Los Andes 32:28-37.

Salgado-Gálvez MA, Zuloaga D, Velásquez CA, Carreño ML, Cardona OD and Barbat AH. 2014a. Urban Seismic Risk Index for Medellín, Colombia: A Probabilistic and Holistic Approach. Proceedings of the $2^{\text {nd }}$ European Conference on Earthquake Engineering and Seismology. Istanbul, Turkey.

Salgado-Gálvez MA, Zuloaga-Romero D, Bernal GA, Mora MG and Cardona OD. 2014b. Fully probabilistic seismic risk assessment considering local site effects for the portfolio of buildings in Medellín, Colombia. Bull. of earthq. eng. 12:671-695.

Salgado-Gálvez MA, Carreño ML, Barbat AH and Cardona OD. 2015a. Evaluación probabilista del riesgo sísmico en Lorca mediante simulaciones de escenarios. Rev. Intern. de método. numér. para calc. y diseño en ing. doi: 10.1016/j.rimni.2014.12.001. In press.

Salgado-Gálvez MA, Bernal GA and Cardona OD. 2015b. Evaluación probabilista de la amenaza sísmica de Colombia con fines de actualización de la Norma Colombiana de Diseño de Puentes CCP-14. Rev. Intern. de método. numér. para calc. y diseño en ing. In press.

Scawthorn C. 2011. Disaster Casualties - Accounting for Economic Impacts and Diurnal Variation. In: Spence R, So E and Scawthorn C (eds), Human Casualties in Earthquakes, pp 51-63. Springer.

Spence R and So E. 2009. Estimating shaking-induced casualties and building damage for global earthquake events. NEHRP Grant number 08HQGR0102. Final technical report.

UNISDR (United Nations International Strategy for Disaster Risk Reduction). 2015. Global Assessment Report on Disaster Risk Reduction. Geneva, Switzerland. 
Velásquez CA, Cardona OD, Mora MG, Yamin LE, Carreño ML and Barbat AH. 2014. Hybrid loss exceedance curve (HLEC) for disaster risk assessment. Nat. Hazards 72:455479.

Wang SY, Li YH, Chi GB, Xiao SY, Ozanne-Smith J, Stevenson M and Phillips MR. 2008. Injury-related fatalities in China: an under-recognized public-health problem. Lancet 372:1765-1773.

WHO (World Health Organization). 2004. The global burden of disease: 2004 update. Geneva, Switzerland.

WHO (World Health Organization). 2013. WHO methods and data sources for global burden of disease estimates 2000-2011. Geneva, Switzerland. 